\title{
Grandparents in Minority Language Maintenance: Mandarin Chinese in Canada
}

\author{
Qin Xiang, Veronika Makarova \\ Department of Linguistics, University of Saskatchewan, Saskatoon, Canada \\ Email: qin.xiang@usask.ca,v.makarova@usask.ca
}

How to cite this paper: Xiang, Q., \& Makarova, V. (2021). Grandparents in Minority Language Maintenance: Mandarin Chinese in Canada. Open Journal of Modern Linguistics, 11, 380-394. https://doi.org/10.4236/ojml.2021.113029

Received: May 16, 2021

Accepted: June 12, 2021

Published: June 15, 2021

Copyright $\odot 2021$ by author(s) and Scientific Research Publishing Inc. This work is licensed under the Creative Commons Attribution International License (CC BY 4.0).

http://creativecommons.org/licenses/by/4.0/

(c) (i) Open Access

\begin{abstract}
This article investigates the role of grandparents in Mandarin Chinese retention by children in Saskatchewan, Canada. The materials for the study come from interviews with 60 Mandarin Chinese/English bi-multilingual children between the ages of 6 and 13 in the families of immigrants from China residing in Saskatchewan, Canada. Additional materials describing bilingual children's Mandarin language proficiency come from a picture description as well as Chinese characters reading and writing tasks. The interview responses and language proficiency parameters were analyzed with the help of correlation analysis, chi-square (for nonparametric data) and univariate ANOVAs (for parametric data). The results are highly controversial, as on the one hand, they demonstrate that the presence of grandparents residing in the same household as their grandchildren is associated with the grandchildren having fewer non-canonical forms (NCFs referred to in earlier research as errors) in their narratives and fewer phonological NCFs. On the other hand, children who have grandparents residing with them are more likely to have a lower ability to read Mandarin texts with PinYin, spend fewer hours reading in Mandarin, produce more incomplete sentences per utterance, and shorter narratives.
\end{abstract}

\section{Keywords}

Mandarin Chinese, Immigrant Language Maintenance, Heritage Language, Grandparents, Canada

\section{Introduction}

This article describes the role of grandparents in the development and maintenance of Mandarin Chinese in their bi/multilingual grandchildren's linguistic repertoire in Canada (in the province of Saskatchewan). The rationale for the 
study comes from the importance of the growing group of Mandarin Chinese speaking immigrants in Canada, lack of earlier investigations of Chinese immigrants in Saskatchewan and insufficient amount of research on the role of grandparents in heritage language maintenance in immigrant families. An additional motivation comes from personal experiences of the authors who have been raising bilingual/multilingual children in Canada with some assistance from grandparents.

The research study reported in this article was not specifically focused on grandparents initially, but was a comprehensive descriptive examination of Mandarin language development in the speech of Mandarin-English bilingual children in Saskatchewan. The results of the study in terms of the grandparents' role were so unexpected that in order to give them sufficient attention, we report them here separately from the rest of the study.

\section{Literature Review}

\subsection{Child Bi/Multilingualism in Immigration Contexts and Family}

In this article, we examine the role of grandparents in the development of a minority heritage language competence by their bi/multilingual grandchildren from the positions of bilingualism/multilingualism, and the studies of heritage language and family language policies.

Some bi/multilingualism research studies demonstrate positive effects of bi/ multilingualism on intellectual development, a sense of well-being (e.g., Berry \& Sam, 2016) and some cognitive functions (e.g., Bialystok, Craik, \& Luk, 2012). However, in case of immigrant populations, reaching and maintaining bi/multilingualism (in the home and host country language(s)) takes an effort. Adult immigrants typically have to develop or enhance a proficiency in the majority language(s) upon their arrival in the new home country (e.g., Tannenbaum \& Peleg, 2020). On the other hand, the second generation (the children of adult immigrants) become bi/multilingual in their parent's home country language(s) learnt at home and in the dominant language(s) of the host country learnt outside and at school (Zhang et al., 2018: p. 45). The home language then is described as a "heritage" language. This term may indicate that first, this language is an ancestral language and its speakers may be emotionally connected to it, and second, that this language may become underdeveloped to a larger or lesser degree due to education and later professional communication in the majority language of the country (Polinsky, 2018). A term "subtractive bilingualism" has also been employed to describe a gradual loss of proficiency in the home language of bilinguals (Lambert, 1981; Zhang et al., 2018: p. 45). By the third generation, a shift towards the majority language is frequently completed in immigrant families (due to intermarriages and other factors) (Zhang et al., 2018: p. 45).

Among the factors that determine whether an immigrant (heritage) home language is maintained or lost, family and family language policies have been 
identified as playing a crucial role. Family Language Policies (FLP) are related to "how a family views and organises language use" (Hollebeke et al., 2020: p. 1). They include "beliefs about and attitudes towards language(s) and language use, language practices (language(s) used in families' daily interactions and employed strategies), and language management efforts to shape the language use and learning outcomes" (Hollebeke et al., 2020: p. 2). Indeed, the quality and quantity of language input are prerequisites of any kind of successful language acquisition (whether mono-, bi- or multilingual) (Gathercole, 2016; Montrul, 2016). In case of immigrant families, children can only develop a proficiency in the heritage language if it is spoken at home. Of course, the role of linguistic community, peers speaking the heritage language, education in the heritage language, teachers, peers, and community members also add to the input as well as to learner motivation (Pearson, 2007; Zhang et al., 2018). As children in immigrant families grow up, the amount of communication with parents in the heritage language decreases, and the role of peer communication increases (Jia et al., 2014).

However, at the early stages of language acquisition, it is primarily parents' language attitudes, their will (if any) to provide the home country language(s) environment at home, and their specific ways of taking care of language teaching that provide a chance for the home language to be passed over to their children despite the pressures of the majority language(s) from the outside. In most studies, the parents' determination and actions to teach the heritage language to their children is referred to as family language polices or parental language policies (e.g., Hollebeke et al., 2020; Hirsch \& Lee, 2018) and in a few others-as parental ethnic socialization practices (e.g., Luo \& Wiseman, 2000). The use of a heritage language at home (e.g., Mandarin Chinese in Singapore) is associated with "greater use and proficiency in Mandarin, as well as ... more positive attitudes and motivation" towards the language and its learning (Cavallaro et al., 2021: p. 126). In short, a family is a stronghold of language maintenance and enculturation (Cavallaro et al., 2021: p. 126).

As far as the roles of family members are concerned, some studies specifically examined the roles of immigrant mothers and their linguistic beliefs and policies in passing the language over to their children (Kwon, 2017). For example, in Chinese immigrant families parenting, mothers practice shaming/love withdrawal more than the fathers (Chen, Sun, \& Yu, 2017). The attitudes to parental roles in communities may also distinguish between the expected roles of mothers and fathers. For example, in some communities, bilingual parenting is seen as the responsibility of mothers (e.g., Piller \& Gerber, 2018). In some other communities (e.g., Arab immigrants in New Zealand), fathers are expected to play a prominent role in defining family language planning and its resources (Al-Sahafi, 2015).

Besides parents, the major "influencers" in the heritage language maintenance in immigrant families are siblings (Duursma et al., 2007; Cho, 2018). For example, children in Chinese Singaporean families speak more Mandarin than English with their siblings, particularly with younger ones (Cavallaro et al., 2021). 
Similarly, the presence of older siblings who are fluent speakers of the minority language fosters the language proficiencies among younger siblings (Luykx, 2003). The bi/multilingual children themselves were also identified as participating agents in FLP whereby their language attitudes affect their heritage language proficiency (Piller \& Gerber, 2018; Schwartz, 2012; Spolsky, 2019).

By contrast, the impact of other family members, particularly of grandparents has hardly received any attention in bilingualism research. Grandparents in earlier research are seen mostly as one of the motivations for children to learn the HL "to communicate with grandparents" (Park \& Sarkar, 2007: p. 223; Little, 2020). One fundamental investigation of the role of grandparents in HL maintenance by children was conducted in Korean-Americans families by Park (2006). The results show that parents believe that grandparents are seen as a linguistic and cultural resource and that they have an impact on children's cultural practices and language use. Spolsky (2019: p. 3) indicates that grandparents are one of the factors influencing the family domain and categorizes them as one of the "internal pressures". This paucity of information about grandparents' role in HL maintenance is probably explained by the following reasons. First, grandparents do not fit into the Western idea of a nuclear family. Second, not very many immigrant families can manage to have grandparents residing with them.

\subsection{Mandarin Chinese as a Heritage Language among Child $\mathrm{Bi} /$ Multilinguals in North America}

In heritage language research in North American contexts, studies of Mandarin Chinese/English bi-/multilinguals are among the most frequent (Hollebeke et al., 2020). This is a reflection of the fact that Mandarin Chinese is the second most common home language in the USA (Park, Zong, \& Batalova, 2018), and the first one in Canada (610,835 individuals) (Statistics Canada, 2016). In Canada, Mandarin Chinese has very high retention rates of over 80\% (Statistics Canada, 2016).

The studies of Mandarin Chinese retention in North American contexts show that for most part, the first immigrant generation of parents value their language "as a resource and take positive actions to maintain the HL in the next generation", but their children do not always see the relevance of the HL and may resist the parental language teaching efforts (Zhang \& Slaughter-Defoe, 2009; Zhang, 2010) even despite authoritarian (or "tiger") parenting widely practiced in Chinese immigrant families (Chen et al., 2014; Cheah, Leung, \& Zhou, 2013). To support Mandarin language learning, parents often enroll their children in Chinese language schools (Smith \& Li, 2020). In cases when parents are reluctant to use the heritage language because of the outside pressures of the majority language, their children are not likely to develop proficiency in it (Shin, 2010: p. 203).

A study considering the role of grandparents in Chinese language maintenance in Montreal, Canada, suggests that grandparents are interested in Chinese language maintenance by their grandchildren, and that they take an active role 
taking care of grandchildren (Zhang, 2009). In a study conducted in Toronto, young Chinese speaking adults identified grandparents as a group who communicated with them in Chinese the most (Man, 2006). However, neither of the above studies considered a relationship between language proficiency and the presence of grandparents.

In sum, very little is known about the possible connection between communication with grandparents and grandchildren's heritage language proficiency in general as well as in Mandarin Chinese as a HL in North America. The very few available studies in Canadian context did not pursue the quantitative aspect, and were conducted in the settings of two major megapolises. The aim of this article is to add some additional data to the picture of the role of grandparents in Mandarin Chinese HL maintenance by grandchildren residing in Saskatchewan (SK), the central of the Canadian prairies provinces, where the Chinese community is small. In particular, the goals of the study were to establish how many children in SK have grandparents residing with them; whether the presence of grandparents may provide a boost to the motivation of children to learn Mandarin, and whether additional amount and depth of language input are provided by grandparents that could translate to enhanced Mandarin language proficiency of their grandchildren. We were also interested to know what language learning-related activities the grandparents could engage with their grandchildren.

The following research questions reflect the above goals of the study:

- How common is it for Chinese grandparents to spend time with their grandchildren in SK, Canada?

- Is the presence of grandparents connected with language proficiencies of Mandarin-English bilinguals in SK?

- Is the presence of grandparents connected with language attitudes of children?

- What are the language and/or culture activities that grandparents may facilitate?

\section{Materials and Methods}

\subsection{Research Design Approach and Methods}

The approach to research design is Variationist Sociolinguistics (e.g. Tagliamonte, 2012) that reveals relationships between linguistic parameters and social parameters combined with sociolinguistic investigations of language attitudes and family language policies (e.g., Makarova, Terekhova, \& Mousavi, 2019).

The methods employed in our study included:

- an interview study of language use, attitudes and exposure of bi/multilingual child participants from immigrant families in Saskatchewan where Mandarin Chinese was a home language;

- an assessment of children's Mandarin Chinese speech proficiency parameters that included counts of Non-Canonical Forms (NCFs), a term which is preferred in many contemporary studies instead of punitive "errors" (e.g., An- 
tomo \& Müller, 2018: p. 5);

- a survey administered to parents;

- a statistical analysis of the co-variance of the presence/absence of grandparents in the households as well as languages spoken by the grandparents with children's proficiency parameters and language attitudes (Spearman's Rho, two-tailed);

- Chi-square tests of the children's language use and attitudes (extracted from the interviews) split by two groups (with and without grandparents present in the household); and

- univariate ANOVA tests of the children's language proficiencies split by two groups (with and without grandparents present in the household).

\subsection{Participant Eligibility Criteria and Recruitment}

Eligibility criteria for the child participants in the study were set as follows:

- they had to be either born in Canada, or brought to Canada by the age of three;

- they had at least one parent who was born in China and immigrated to Canada after his/her adulthood;

- they could speak Mandarin Chinese and English; and

- they were in the age groups between 5 to 7 years old or 10 to 12 years old.

Parents of bilingual/multilingual children were recruited by purposeful sampling via advertisements posts in both Chinese and English circulated within Saskatoon Chinese community. Saskatoon location allowed to involve participants from an area with a small Chinese community demographics, as opposed to earlier research that focused on immigrants in megapolises. The participation was voluntary, no remuneration was provided.

\subsection{Interview Questions and Questionnaire Construction}

Interview questions and the survey were compiled following previous studies (e.g., Makarova et al., 2019). The interview questions included language use and attitudes questions, as well as questions about the primary person at home who teaches them Chinese. The survey included a question about the presence of grandparents in the same household. The interviews were conducted in the language preferred by the child participant.

The survey administered to parents included multiple parameters related to parents' language attitudes, their demographic data, language use inside and outside home, etc. However, in this article, we only utilize parent surveys to extract data about live-in grandparents and the languages spoken by grandparents at home.

\subsection{Language Proficiency Assessment}

Language proficiency assessment included an evaluation of writing, reading and speaking Mandarin skills. To make an assessment of writing skills, the children 
were provided with a piece of paper and requested to write as many Chinese characters as they could think of in 1.5 minutes (both the total number and the number of characters written correctly were measures of writing proficiency). The children's reading assessment was performed through offering them two versions of a text (with and without PinYin) and requesting them to read a few lines from both texts if they could. Respectively "being able/unable to read a text with/without PinYin" were binary measures of reading proficiency. Speaking proficiency was assessed via a picture prompted narrative, a commonly employed tool allowing to gather data from participants with very different levels of proficiency (Makarova et al., 2019). The picture prompts were a set of twelve pictures of “the tortoise and the hare/龟兔赛跑”

(http://www.ibigtoy.com/books/index.php).

The measures of speaking proficiency were as follows:

- total number of words in the narrative (total vocabulary produced);

- vocabulary size (total number of different lexical items);

- number of distinct lexemes (total number of different nouns, verbs, classifiers, grammatical particles, final particles and phrases);

- average number of words per utterance (utterance length);

- average number of words per sentence (sentence length);

- number of clauses;

- number of incomplete sentences;

- number of complete sentences;

- number of simple sentence;

- number of complex and compound sentences;

- number of NCFs (split by lexical, grammar, and phonological NCFs);

- speech rate (average number of words per total seconds); and

- speech fluency (average number of pauses per total utterances).

\subsection{Participant Demographic Parameters}

Child participant demographic parameters are summarized below in Table 1. Out of a total of 60 child participants, thirty-nine spoke Mandarin and English, and twenty-one also spoke one of the other Chinese languages (or dialects, according to the Chinese tradition). For simplicity, we will use the word "dialect" for all Chinese languages other than Mandarin. Forty-five (out of 60) participants were multilingual in languages other than Mandarin, dialects and English: forty children spoke French; three-Spanish; one-Japanese; and one-German.

Table 1. Child participant demographics.

\begin{tabular}{cccccccc}
\hline \multirow{2}{*}{ Gender } & \multicolumn{7}{c}{ Age } \\
\cline { 2 - 8 } & Age 5 & Age 6 & Age 7 & Age 10 & Age 11 & Age 12 & Total \\
\hline Girls & 4 & 7 & 11 & 8 & 4 & 0 & 34 \\
Boys & 3 & 3 & 2 & 7 & 6 & 5 & 26 \\
Total & 7 & 10 & 13 & 15 & 10 & 5 & 60 \\
\hline
\end{tabular}




\section{Results}

\subsection{Grandparents Living in the Same Household and the Languages They Speak}

According to the parents' survey, twenty-seven (out of sixty) households had grandparents living with them at the time of the survey. Out of these 27 households, grandparents' first language was Mandarin in 16 (59\%), and dialects-in $11(49 \%)$ cases. Chinese dialects spoken by grandparents and by children overlapped only in 4 cases (out of 11 grandparents and 17 children speaking dialects in addition to Mandarin). These common dialects spoken by children and their grandparents were Cantonese ( 3 cases) and Shandong (1).

The use of languages in the family between generations is represented in $\mathrm{Ta}$ ble 2. As Table 2 shows, at home, most parents and grandparents speak with each other in Mandarin, and a few-in a dialect. According to interviews with children, grandparents and grandchildren speak in Mandarin, and a few-in a dialect, both at home and outside. No parents or grandparents speak with each other or grandchildren in English.

Not surprisingly, children who had their grandparents living with them, felt closer to grandparents than children who lived separately from their grandparents (the latter residing in China), as shown in a chi-square test:

$$
\chi^{2}(1, N=27)=13.1, p<0.001 \text {. }
$$

\subsection{Grandparents Living in the Same Household and Grandchildren's Mandarin Exposure and Proficiency Parameters}

The following language exposure and proficiency parameters are related to having grandparents living in the same household:

- Number of hours spent by children reading in Mandarin (chi-square):

$$
\chi^{2}(1, N=27)=9.4949, p=0.049851 .
$$

- Reading with PinYin (Spearman Rho):

$$
r_{s}(27)=-0.28, p=0.026 \text {; }
$$

(chi-square):

$$
\chi^{2}(1, N=27)=4.97, p=0.025
$$

Table 2. Language use at home between (a) parents and grandparents (as reported by parents) and (b) grandparents and grandchildren (as reported by children).

\begin{tabular}{cccccc}
\hline \multirow{2}{*}{ Participant Number } & \multicolumn{4}{c}{ Language Use } \\
\cline { 2 - 6 } & Mandarin $\begin{array}{c}\text { Mandarin } \\
\text { and English }\end{array}$ & English & Dialect & Total \\
\hline Panrents and grandparents at home & $20(74 \%)$ & 0 & 0 & $7(26 \%)$ & 27 \\
Parents and grandchildren at home & $24(89 \%)$ & 0 & 0 & $3(11 \%)$ & 27 \\
Grandparents and grandchildren at home & $24(89 \%)$ & 0 & 0 & $3(11 \%)$ & 27 \\
\hline
\end{tabular}


- Narrative length in words (Univariate ANOVA):

$$
F(2,26)=4.03, p=0.049
$$

- Number of incomplete sentences per utterance (Spearman Rho):

$$
r_{s}(27)=0.31, p=0.014 \text {. }
$$

- Total number of NCFs (errors, according to earlier research) (Spearman Rho):

$$
r_{s}(27)=-0.29, p=0.021
$$

(Univariate ANOVA):

$$
F(2,26)=11.02, p=0.001 \text {. }
$$

- Total number of phonological NCFs (Spearman Rho):

$$
r_{s}(27)=-0.25, p=0.046 \text {. }
$$

The above results indicate that if grandparents are living in the same household, children spend less time reading in Mandarin; they are less likely to be able to read with PinYin; they have a higher number of incomplete sentences per utterance in narratives and marginally shorter narratives. On the other hand, if grandparents are living with them, children are less likely to produce NCFs in general, and phonological NCFS.

The first language of grandparents correlated with only one speech proficiency parameter:

- Total number of tone NCFs (Spearman Rho):

$$
r_{s}(27)=0.399, p=0.039 \text {. }
$$

This result suggests that the more children talk with their grandparents whose first language is not Mandarin, the more they can get confused about tones, since Mandarin and Chinese dialects differ by tone's types and use.

\subsection{The Major Agents of Mandarin Chinese Input at Home}

When asked in interviews, from which family member they mostly learn Mandarin at home, 56 children (out of 60) provided responses that are summarized in Table 3.

The results demonstrate that either mothers or both parents are primary

Table 3. Primary Mandarin input provider at home (as identified by children).

\begin{tabular}{cc}
\hline Primary Mandarin input provider & Number of Responses \\
\hline Mother & 21 \\
Father & 7 \\
Parents & 17 \\
Parents and grandparent(s) & 6 \\
Grandparent(s) & 3 \\
Self-studies & 2 \\
Total & 56 \\
\hline
\end{tabular}


Mandarin input providers in the families. Out of 27 households with grandparents, grandparents were identified as a primary family member from whom children learn Mandarin in three cases, and in six more families' grandparents were primary language input providers together with parents. In total, grandparents were named as major Mandarin input providers in $9(1 / 3)$ of the 27 households where grandparents were present.

When asked, what specific language learning activities their primary Mandarin language input providers engage with children, the child participants who identified grandparents as major input providers gave the following responses.

What Grandparents teach if children learn Chinese primarily from them at home:

- write characters; write characters down if do not remember; read textbook; practice with characters exercise book; record the unknown Chinese words into a notebook; watch Chinese TV shows;

- read books to me;

- read books; get paper-cards to practice; use a workbook; read story in Chinese.

What parents and grandparents teach if children learn Chinese primarily from them at home:

- one day say one new word, its meaning and teach new word; someday: give a sheet and write something on it and tell to repeat and write;

- learn from book and textbook; learn words by telling the meaning and tell them back and write; review the words and recite them; poems; I speak and they correct;

- they speak and ask and learn from communication; tell to write and how to write characters;

- learn words form workbook, play mah-jong, tell names from workbook; work, call, write, memorization from workbook, sometimes gets boring;

- recognize more characters, teach poems, supervise Chinese homework, practice writing Chinese, read story in Chinese, speak in Chinese to communicate;

- recite and test; read and recognize; mother tell the stories, help to recognize PinYin, and take me to the libraries to pick up the books together and read and borrow the book.

\subsection{Children's Understanding of Mandarin Spoken by Grandparents}

When asked, how much of Mandarin spoken by their mothers, fathers, grandparents (present in the household), relatives on the phone and people in China children could understand, they produced responses summarized in Table 4.

As Table 4 demonstrates, children's comprehension of their parents' and grandparents' speech is similar, whereas their comprehension of relatives (in talking with them on the phone) and of people they met in China is somewhat worse. However, a chi-square analysis did not reveal any significance between 
Table 4. The amount of Mandarin that child participants could understand (by speaker/speaker group).

\begin{tabular}{ccccccc}
\hline \multirow{2}{*}{$\begin{array}{c}\text { Child's } \\
\text { comprehension of }\end{array}$} & \multicolumn{6}{c}{ The amount of Mandarin that child participants could understand } \\
\cline { 2 - 7 } & All & Most & Half & A little & None & Total \\
\hline Mother & 28 & 26 & 6 & 0 & 0 & 60 \\
Father & 26 & 27 & 7 & 0 & 0 & 60 \\
Grandparents & 13 & 11 & 2 & 1 & 0 & 27 \\
Relatives (phone-calls) & 21 & 20 & 8 & 4 & 0 & 53 \\
In China & 16 & 25 & 12 & 4 & 0 & 57 \\
\hline
\end{tabular}

comprehension by speaker/speaker group. "The amount of Mandarin language that children understand when their grandparents speak to them" correlated with two language proficiency parameters:

- Total number of different grammatical particles, $r(27)=0.398, p=0.040$; and

- Total number of Chinese characters written, $r(27)=0.438, p=0.022$.

Four children volunteered some reasons why they could not understand the Mandarin language spoken by their grandparents. These were "dialects" (identified by two children) and "hard, complex and new words" (mentioned by another two children).

\section{Discussion}

A surprisingly high number of households (45\%) had grandparents living under the same roof at the time of the survey. This could probably be explained by a shortage and high costs of childcare in Saskatchewan. Chinese immigrant parents "import" grandparents from China on visitors' visas to stay with them and help them out with childcare and household chores.

Grandparents were identified as individuals from whom children mostly learn Mandarin by $1 / 3$ of child participants who lived with grandparents. While parents maintain an "essential role in heritage language usage as the foremost agents in transmitting heritage language contents to their children" in general and specifically in Chinese immigrant contexts (Mu \& Dooley, 2015; Zhang et al., 2018: p. 53), it appears that grandparents also have a moderate role in creating an additional Mandarin input.

However, what could be the reasons for a low amount of covariance between the presence of grandparents and children's language proficiency parameters? From personal observations in Chinese immigrant communities, grandparents could be helping more with household chores than teaching Mandarin to grandchildren. Grandmothers could be more involved into Mandarin language teaching than grandfathers, but this needs verification in future research.

Another reason for little connection between the presence of grandparents and grandchildren's language proficiency could be relatively short periods of 
grandparents' stay with their grandchildren, i.e., usually up to six months per year due to the restrictions on visitor visa in Canada. Travel is expensive, so not all families can afford inviting a grandparent every year.

A relatively low impact of grandparents' presence on Mandarin proficiency can also be explained by other factors with much stronger impact overriding the grandparents' effect. The factors with strong impact on heritage language acquisition outside of family and home domain include peers (Jia et al., 2014); community (Pearson, 2007), and ethnic language schools (e.g., Mu \& Dooley, 2015).

The study is limited by the number of participants and the amount of information about grandparents and grandparent-grandchild interactions. The methods of the study (sociolinguistic interviews coupled with measures of language proficiency parameters) cannot reveal the depth of interactions happening in the families. In future, longitudinal studies with audio-recordings of daily interactions within the family in conjunction with more in-depth interviews of both children and grandparents can shed more light on the amount and type of interactions occurring between grandparents and grandchildren.

\section{Conclusion}

The amount and the efficiency of education in languages other than English in English-dominant societies (like Western Canada) have been severely criticized in earlier studies (Piller \& Gerber, 2018: p. 623). This means that those immigrant parents who wish to pass over their language to children have a job cut out for them, as they have very little support from the governments. As shown in earlier research, immigrants from China are typically strongly motivated to pass their language(s) to their children, whereas children could sometimes resist their parents' attempt to encourage them to use the mother tongue (Zhang \& Slaughter-Dafoe, 2009).

In this uphill struggle by parents, any additional resources are welcome, and grandparents appear to be a logical potential expansion of the language input resources. Indeed, as our study shows, in one-third of the households where grandparents resided with the family, children identified their grandparents (exclusively or in combination with parents) as the primary "teachers" of Mandarin Chinese. The role of grandparents in providing the language input is versatile. They can assist grandchildren with learning and practicing characters, reading, learning new Mandarin words. Grandparents and grandkids also relax together watching Chinese TV shows. It is not clear from this study why the presence of grandparents does not directly connect to grandchildren's Mandarin speaking fluency, or their vocabulary size, grammar or the knowledge of characters. However, the presence of grandparents in the household is associated with fewer non-canonical forms in general and fewer phonological NCFs in their grandchildren's narratives. It appears that the role of grandparents in heritage language development by immigrant children and youth is a productive area for future research with different methodologies that could allow a direct examina- 
tion of communicative, game, traditions practice and other forms of interaction between grandparents and grandchildren in immigrant families in general, and in the families of immigrants from China in particular.

\section{Conflicts of Interest}

The authors declare no conflicts of interest regarding the publication of this paper.

\section{References}

Al-Sahafi, M. (2015). The Role of Arab Fathers in Heritage Language Maintenance in New Zealand. International Journal of English Linguistics, 5, 73-83. https://doi.org/10.5539/ijel.v5n1p73

Antomo, M., \& Müller, S. (2018). Non-Canonical Verb Positioning in Main Clauses (Vol. 25). Tübingen: Helmut Buske Verlag.

Berry, J. W., \& Sam, D. L. (2016). Theoretical Perspectives. In D. L. Sam, \& J. W. Berry (Eds.), The Cambridge Handbook of Acculturation Psychology (pp. 11-29, 2nd ed.). Cambridge: Cambridge University Press. https://doi.org/10.1017/CBO9781316219218.003

Bialystok, E., Craik, F. I., \& Luk, G. (2012). Bilingualism: Consequences for Mind and Brain. Trends in Cognitive Sciences, 16, 240-250. https://doi.org/10.1016/j.tics.2012.03.001

Cavallaro, F., Elsie, T. Y. X., Wong, F., \& Ng, B. (2021). “Enculturalling” Multilingualism: Family Language Ecology and Its Impact on Multilingualism. International Multilingual Research Journal, 15, 126-157. https://doi.org/10.1080/19313152.2020.1846833

Cheah, C. S. L., Leung, C. Y. Y., \& Zhou, N. (2013). Understanding “Tiger Parenting” through the Perceptions of Chinese Immigrant Mothers: Can Chinese and U.S. Parenting Coexist? Asian American Journal of Psychology, 4, 30-40. https://doi.org/10.1037/a0031217

Chen, J. J., Sun, P. Z., \& Yu, Z. W. (2017). A Comparative Study on Parenting of Preschool Children between the Chinese in China and Chinese Immigrants in the United States. Journal of Family Issues, 38, 1262-1287. https://doi.org/10.1177/0192513X15619460

Chen, S. H., Hua, M., Zhou, Q., Tao, A., Lee, E. H., Ly, J., \& Main, A. (2014). Parent-Child Cultural Orientations and Child Adjustment in Chinese American Immigrant Families. Developmental Psychology, 50, 189-201. https://doi.org/10.1037/a0032473

Cho, H. (2018). Korean-English Bilingual Sibling Interactions and Socialization. Linguistics and Education, 45, 31-39. https://doi.org/10.1016/j.linged.2018.03.004

Duursma, E., Romero-Contreras, S., Szuber, A., Proctor, P., Snow, C., August, D., \& Calderón, M. (2007). The Role of Home Literacy and Language Environment on Bilinguals English and Spanish Vocabulary Development. Applied Psycholinguistics, 28, 171-190. https://doi.org/10.1017/S0142716406070093

Gathercole, V. C. M. (2016). Factors Moderating Proficiency in Bilingual Speakers. In E. Nicoladis, \& S. Montanari (Eds.), Bilingualism across the Lifespan: Factors Moderating Language Proficiency (pp. 123-140). Berlin: De Gruyter Mouton. https://doi.org/10.1037/14939-008

Hirsch, T., \& Lee, J. S. (2018). Understanding the Complexities of Transnational Family 
Language Policy. Journal of Multilingual and Multicultural Development, 39, 882-894. https://doi.org/10.1080/01434632.2018.1454454

Hollebeke, I., Struys, E., \& Agirdag, O. (2020). Can Family Language Policy Predict Linguistic, Socio-Emotional and Cognitive Child and Family Outcomes? A Systematic Review. Journal of Multilingual and Multicultural Development, 40, 1-32.

https://doi.org/10.1080/01434632.2020.1858302

Jia, G., Chen, J., Kim, H., Chan, P. S., \& Jeung, C. (2014). Bilingual Lexical Skills of School-Age Children with Chinese and Korean Heritage Languages in the United States. International Journal of Behavioral Development, 38, 350-358.

https://doi.org/10.1177/0165025414533224

Kwon, J. (2017). Immigrant Mothers' Beliefs and Transnational Strategies for Their Children's Heritage Language Maintenance. Language and Education, 31, 495-508. https://doi.org/10.1080/09500782.2017.1349137

Lambert, W. E. (1981). Bilingualism and Language Acquisition. Annals of the New York Academy of Sciences, 379, 9-22. https://doi.org/10.1111/j.1749-6632.1981.tb41993.x

Little, S. (2020). Whose Heritage? What Inheritance? Conceptualising Family Language Identities. International Journal of Bilingual Education and Bilingualism, 23, 198-212. https://doi.org/10.1080/13670050.2017.1348463

Luo, S. H., \& Wiseman, R. L. (2000). Ethnic Language Maintenance among Chinese Immigrant Children in the United States. International Journal of Intercultural Relations, 24, 307-324. https://doi.org/10.1016/S0147-1767(00)00003-1

Luykx, A. (2003). Weaving Languages Together: Family Language Policy and Gender Socialization in Bilingual Aymara Households. In R. Bayley, \& S. Schecter (Eds.), Language Socialization in Bilingual and Multilingual Societies (pp. 25-43). Clevedon: Multilingual Matters. https://doi.org/10.21832/9781853596377-005

Makarova, V., Terekhova, N., \& Mousavi, A. (2019). Children's Language Exposure and Parental Language Attitudes in Russian-as-a-Heritage-Language Acquisition by Bilingual and Multilingual Children in Canada. International Journal of Bilingualism, 23, 457-485. https://doi.org/10.1177/1367006917740058

Man, E. Y. (2006). First Language Use and Language Behavior of Chinese Students in Toronto, Canada. In K. Kondo-Brown (Ed.), Heritage Language Development: Focus on East-Asian Immigrants (pp. 33-56). Amsterdam: John Benjamins. https://doi.org/10.1075/sibil.32.14man

Montrul, S. (2016). Age of Onset of Bilingualism Effects and Availability of Input in First Language Attrition. In E. Nicoladis, \& S. Montanari (Eds.), Bilingualism across the Lifespan: Factors Moderating Language Proficiency (pp. 141-161). Berlin: De Gruyter Mouton. https://doi.org/10.1037/14939-009

Mu, G. M., \& Dooley, K. (2015). Coming into an Inheritance: Family Support and Chinese Heritage Language Learning. International Journal of Bilingual Education and Bilingualism, 18, 501-515. https://doi.org/10.1080/13670050.2014.928258

Park, M., Zong, J., \& Batalova, J. (2018). Growing Superdiversity among Young US Dual Language Learners and Its Implications. Washington DC: Migration Policy Institute.

Park, S. M., \& Sarkar, M. (2007). Parents' Attitudes toward Heritage Language Maintenance for Their Children and Their Efforts to Help Their Children Maintain the Heritage Language: A Case Study of Korean-Canadian Immigrants. Language, Culture and Curriculum, 20, 223-235. https://doi.org/10.2167/lcc337.0

Park, Y. (2006). Sojourner Families' Perceptions of Bilingual/Bicultural Development in School-Age Children: An Exploration of the Experiences of Korean Graduate Student Families While Residing in the United States. Doctoral Dissertation, Bloomington, IN: 
Indiana University.

Pearson, B. Z. (2007). Social Factors in Childhood Bilingualism in the United States. Applied Psycholinguistics, 28, 399-410. https://doi.org/10.1017/S014271640707021X

Piller, I., \& Gerber, L. (2018). Family Language Policy between the Bilingual Advantage and the Monolingual Mindset. International Journal of Bilingual Education and Bilingualism, 24, 622-635. https://doi.org/10.1080/13670050.2018.1503227

Polinsky, M. (2018). Heritage Languages and Their Speakers. Cambridge: Cambridge University Press. https://doi.org/10.1017/9781107252349

Schwartz, M. (2012). Second Generation Immigrants: A Socio-Linguistic Approach of Linguistic Development within the Framework of Family Language Policy. In M. Leikin, M. Schwartz, \& Y. Tobin (Eds.), Current Issues in Bilingualism: Cognitive and Socio-Linguistic Perspectives (pp. 119-135, Vol. 5). Dordrecht: Springer. https://doi.org/10.1007/978-94-007-2327-6_6

Shin, S. J. (2010). "What about Me? I'm Not like Chinese But I'm Not like American": Heritage-Language Learning and Identity of Mixed-Heritage Adults. Journal of Language, Identity, and Education, 9, 203-219. https://doi.org/10.1080/15348458.2010.486277

Smith, S. A., \& Li, Z. (2020). Closing the Enjoyment Gap: Heritage Language Maintenance Motivation and Reading Attitudes among Chinese-American Children. International Journal of Bilingual Education and Bilingualism, 1-18. https://doi.org/10.1080/13670050.2020.1742653

Spolsky, B. (2019). A Modified and Enriched Theory of Language Policy (and Management). Language Policy, 18, 323-338. https://doi.org/10.1007/s10993-018-9489-z

Statistics Canada (2016). https://www12.statcan.gc.ca/census-recensement/2016/as-sa/98-200-x/2016010/98-200 -x2016010-eng.cfm

Tagliamonte, S. A. (2012). Variationist Sociolinguistics: Change, Observation, Interpretation. Oxford: Wiley-Blackwell.

Tannenbaum, M., \& Peleg, G. (2020). Language and Identity among Iranian Immigrants in Israel. Journal of Multilingual and Multicultural Development, 41, 764-778. https://doi.org/10.1080/01434632.2019.1653884

Zhang, D. (2010). Language Maintenance and Language Shift among Chinese Immigrant Parents and Their Second-Generation Children in the US. Bilingual Research Journal, 33, 42-60. https://doi.org/10.1080/15235881003733258

Zhang, D., \& Slaughter-Defoe, D. T. (2009). Language Attitudes and Heritage Language Maintenance among Chinese Immigrant Families in the USA. Language, Culture, and Curriculum, 22, 77-93. https://doi.org/10.1080/07908310902935940

Zhang, J. (2009). Chinese Heritage Language Maintenance: A Grandparents' Perspective. Doctoral Dissertation, Montréal: McGill University.

https://www.academia.edu/32368250/Chinese_heritage_language_maintenance_A_gra ndparents_perspective

Zhang, J., Dennis, J. M., \& Houseman, C. (2018). The Role of Family and Community Bicultural Socialization in the Bilingual Proficiency of Immigrant Young Adults. International Journal of Intercultural Relations, 67, 44-57.

https://doi.org/10.1016/j.ijintrel.2018.09.003 